\title{
Model-Based Decision Support Tools at Jugos S.A. Concentrated Fruit Juice Plant
}

\author{
Aníbal M. Blanco, ${ }^{a}$ M. Susana Moreno, ${ }^{a}$ Carolina Taraborelli, ${ }^{a}$ Flavio D’Angelo, ${ }^{\text {b,c }}$ Facundo Iturmendi, ${ }^{\text {b,c }}$ J. Alberto Bandoni ${ }^{a}$ \\ a Planta Piloto de Ingeniería Química - PLAPIQUI (Universidad Nacional del Sur - CONICET), Bahía Blanca 8000, Buenos Aires, \\ Argentina; ${ }^{\mathbf{b}}$ Jugos S.A., Parque Industrial, Villa Regina 8336, Río Negro, Argentina; ${ }^{\mathbf{c}}$ Universidad Nacional de Río Negro, CIT Río \\ Negro 8336, Río Negro, Argentina \\ Contact: ablanco@plapiqui.edu.ar (AMB); smoreno@plapiqui.edu.ar, (iD https://orcid.org/0000-0001-5744-5586 (MSM); \\ ctaraborelli@plapiqui.edu.ar (CT); fdangelo@jugos-sa.com.ar (FD); fiturmendi@unrn.edu.ar (FI); abandoni@plapiqui.edu.ar, \\ (iD) https://orcid.org/0000-0002-9475-3825 (JAB)
}

Received: November 29, 2019

Revised: March 28, 2020

Accepted: May 20, 2020

Published Online in Articles in Advance: July 10,2020

https://doi.org/10.1287/inte.2020.1045

Copyright: (c) 2020 INFORMS

\begin{abstract}
We describe the development of a decision-support tool to assist in the operations of a large concentrated apple and pear juice plant. The tool's objective is to generate detailed schedules of clarified juice batches to be produced in the following weeks considering incoming fruit forecasts, commercial commitments, and infrastructural constraints. The tool is based on two interactive modules, PLANNER and SIMOPT, with different and complementary purposes. Each module is based on mixed-integer models with specific inputs, outputs, and user interfaces. PLANNER consists of three submodules: (i) planning assigns a batch of concentrated juice to be produced on a specific day, taking into account cleaning activities, rest days, raw material availability, and production and storage constraints; (ii) preprocessing organizes juice orders in batches; and (iii) pooling provides a detailed monitoring of semielaborated juice in storage pools in terms of inventories and sugar and acid content. Finally, SIMOPT provides a detailed optimal operative condition of the plant together with a thorough calculation of specific costs. This information is used by PLANNER to evaluate the corresponding economic objective functions. Besides providing optimal target conditions to the plant and feasible production schedules, the developed tools generate production guidelines in the long term and allow performing scenario studies.
\end{abstract}

History: This paper was refereed.

Keywords: concentrated fruit juice $\bullet$ decision making $\bullet$ batch scheduling $\bullet$ production planning $\bullet$ mixed-integer nonlinear programming

\section{Introduction}

The pome fruit industry supply chain (FISC) is a complex system that involves many actors: pome fruit (i.e., apples and pears) production farms, packaging plants, concentrated juice plants, refrigeration facilities, and transport companies. The whole system is driven by seasonal fruit availability with the aim of producing a few basic products: packed apples, packed pears, concentrated apple juice, and concentrated pear juice. However, because there exist several apple and pear varieties, two basic types of fruit production (traditional and organic), two basic kinds of cold storage (conventional and controlled atmosphere), and a large number of possible packaging options for both fresh fruit and concentrated juice, the number of different products is actually vast.

There are a large number of decisions to be made in each node of the chain in a daily fashion. Such decisions involve the amounts of fruit transferred between the nodes and the volumes to be processed within each node to produce each one of the large numbers of products to satisfy commercial commitments and on-the-spot demands. One characteristic feature of this system, which makes decision making a challenging activity, is the significant uncertainty in both extremes of the chain. On one side, fruit availability heavily depends on weather conditions, making, for example, one or more specific fruit varieties more or less abundant in a particular year. On the other extreme, because most products of the chain are subject to worldwide competition, prices and demands fluctuate, which largely affects the economics of the business. In recent years, Argentinian manufacturers have had to become competitive and pursue a high-quality product to survive in such a competitive and uncertain environment.

Although most companies of the Argentinian FISC have incorporated many technological innovations in the last 20 years (e.g., equipment, control and monitoring, automation) to compete at worldwide standards, decision making still remains a largely artisanal activity based on managers' experience and intuition with the aid of spreadsheets at most. However, the system has been extensively studied at an academic level for more than 10 years. For example, 